\title{
Differential Expression of Matrix Metalloproteinases and Inhibitors in Developing Rat Lung Mesenchymal and Epithelial Cells
}

\author{
OLIVIER BOUCHERAT, JACQUES R. BOURBON, ANNE-MARIE BARLIER-MUR, BERNADETTE CHAILLEY-HEU, \\ MARIE-PIA D'ORTHO, AND CHRISTOPHE DELACOURT
}

\begin{abstract}
INSERM Unité 841, IMRB, Département Biologie et Thérapeutique Cardiorespiratoires et Hépatiques, Créteil, F-94000 France; Université Paris 12, Faculté de Médecine, Créteil, F-94000 France
\end{abstract}

\begin{abstract}
Lung development requires extracellular matrix remodeling. This involves matrix metalloproteinases (MMPs) and their endogenous inhibitors [tissue inhibitors of metalloproteinases (TIMPs)]. Because these have been generally studied only in whole lung, we focused specifically on mesenchymal and epithelial cells freshly isolated at various developmental stages. In fibroblasts, the most striking developmental change was a peak (fourfold the prenatal level) of membrane type 1 (MT1)-MMP transcript during alveolarization, consistent with the known crucial role of MT1-MMP in this process. TIMP-1 and -2 mRNAs transiently increased on postnatal $d$ (pn) 3. In alveolar epithelial cells (AECs), MMP-2 expression was maximal on fetal d (f) 19 when alveolar type II cells (ATII) differentiate and on pn5; by contrast, MT1-MMP expression changed little and TIMP-1 expression decreased with advancing gestation. In cells expressing in vitro the ATI phenotype, TIMP-1 and - 2 activities were nine- and fivefold those in cells expressing ATII features, respectively, whereas ATII presented higher MMP-2 activity and were the only cell type to express MMP-9. This indicates higher remodeling potential for ATII. Pulmonary mesenchymal and epithelial cells have therefore quite distinct MMP/TIMP expression patterns. Changes in cell compartments should be specifically documented in developing lung diseases such as bronchopulmonary dysplasia in which changes in MMP activities have been reported. (Pediatr Res 62: 20-25, 2007)
\end{abstract}

$\mathrm{E}$ xtracellular matrix (ECM) is essential to lung morphogenesis and to cell differentiation, growth, and motility (1). The successive pseudoglandular, canalicular, saccular, and alveolar stages of lung development (2) all involve remodeling of ECM (1). Zinc-dependent endopeptidases, the MMPs, carry out ECM proteolysis (3). Their activity is regulated by various mechanisms in which TIMPs play a prominent role (3).

A variety of MMPs and TIMPs are expressed in the developing lung $(4,5)$. Although epithelial and mesenchymal cells appear to have distinct MMP/TIMP expression features $(4,6)$, expression changes in MMPs and TIMPs across the different developmental steps have generally been studied only in the whole lung $(4,5,7,8)$. When epithelial and mesenchymal cells were studied comparatively, it was for a very limited period

Received November 16, 2006; accepted February 16, 2007

Correspondence: Jacques Bourbon, Ph.D., Inserm U841, Faculté de Médecine, 8 rue du Général Sarrail, 94010 Créteil, France; e-mail: jacques.bourbon@creteil.inserm.fr

This work was supported by regular INSERM funding without extramural source.
(6). The question of relative contributions is all the more important in that reciprocal epithelial-mesenchymal interactions are crucial for all lung developmental steps (9). Moreover, more attention has been paid thus far to early fetal lung development than to later stages. Further documenting late development may help to better understand the significance of changes in MMP activity associated with neonatal chronic lung disease $(10,11)$. In the present study, we investigated expression changes in MMPs/TIMPs in fibroblasts and AECs extemporaneously isolated from the rat lung, from the end of pseudoglandular stage to alveolar stage. We also studied comparatively cells expressing in vitro either the ATI or ATII phenotype.

Because a global study of MMPs and TIMPs could not be considered, we focused on proteins with known particular importance, including MMP-2 and MT1-MMP (or MMP-14) that are involved in alveolar formation (12-14), TIMP-1 (the major MMP inhibitor), and TIMP-2, which controls MMP-2 activation (15). These are among the most expressed matrixremodeling molecules in the lung, as evidenced in a profiling study in various organs of the developing mouse (5). Because we focused on late development, TIMP-3 that is important earlier during branching morphogenesis (16) was not included.

\section{MATERIALS AND METHODS}

Lung cell isolation. Dated pregnant Sprague-Dawley rats (Charles River, Saint Germain sur 1'Arbresle, France) were used. Animal procedure was authorized by the French Ministry of Agriculture. AECs and fibroblasts were isolated by differential adhesion and centrifugation as described (17), on f17 (pseudoglandular stage), f19 (canalicular stage), f21, and pn1 and 3 (saccular stage), pn5 and 8 (alveolar stage, progressing septation), and pn16 (alveolar stage, terminated septation). Epithelial cells isolated by this procedure express characteristic ATII markers (17). Freshly isolated cells were immediately frozen without any culture step and stored at $-80^{\circ} \mathrm{C}$.

AEC culture. To determine whether cells expressing the ATI or ATII features have different MMP/TIMP equipment, AECs isolated on pn21 were seeded on substrata reported to favor either phenotype. Engelbreth-Holm-

Abbreviations: AECs, alveolar epithelial cells; ATI (II), alveolar type I (type II) cells; CF, collagen-fibronectin coating; CFL, collagen-fibronectinlaminin 5 coating; CM, conditioned medium; EHS matrix, EngelbrethHolm-Swarm basement-membrane matrix; f, fetal day; MMP, matrix metalloproteinase; pn, postnatal day; SP-B, surfactant protein B; TIMP, tissue inhibitor of metalloproteinases 
Table 1. Sequences of primers used to amplify TIMP-1, TIMP-2, MMP-2, and MT1-MMP cDNA fragments

\begin{tabular}{lllr}
\hline & \multicolumn{1}{c}{ Forward $\left(5^{\prime}-3^{\prime}\right)$} & \multicolumn{1}{c}{ Reverse $\left(5^{\prime}-3^{\prime}\right)$} & cDNA length $(\mathrm{bp})$ \\
\hline TIMP-1 & CCAGAAATCATCGAGACCACCT & GGCAGGCAAAGTGATCGCTC & 420 \\
TIMP-2 & ATTTATCTACACGGCCCC & CAAGAACCATCACTTCTCTTG & 341 \\
MMP-2 & TGATCTCCAGTGCCCTC & TGGCGAACACAGCACTC & $55^{\circ} \mathrm{C}$ \\
MT1-MMP & GTACTACCGCTTCAATGAGG & CACTGCCAGTACCAGGAG & $58^{\circ} \mathrm{C}$ \\
\hline
\end{tabular}

Swarm basement membrane matrix [(EHS matrix) prepared in the laboratory] and a coating designated collagen-fibronectin-laminin 5 coating (CFL) composed of collagen I ( $8 \mu \mathrm{g} / \mathrm{cm}^{2}$; BD Biosciences, Erembodegem, Belgium), fibronectin $\left(2.1 \mu \mathrm{g} / \mathrm{cm}^{2}\right.$; Sigma Chemical Co., L'Isle d'Abeau-Chesnes, France), and laminin $5\left(0.5 \mu \mathrm{g} / \mathrm{cm}^{2}\right.$; gift from P. Rousselle, Institute of Protein Biology and Chemistry, CNRS, Lyon, France), both support the ATII phenotype. Plastic and a collagen-fibronectin coating (CF), composed only of collagen I and fibronectin (same concentrations), favor transdifferentiation into ATI $(18,19)$. Purified AECs in $10 \%$ fetal bovine serum (FBS)-containing medium were seeded $\left(1.5 \times 10^{6}\right.$ cells $\left./ \mathrm{mL}\right)$ in multiwell plastic culture plates either uncoated or coated with one of the three matrix substrata. After overnight adhesion to substratum under air- $\mathrm{CO}_{2}(95 \%$ to $5 \%)$, serum-free defined medium (17) was introduced and renewed after $24 \mathrm{~h}$. After $30 \mathrm{~h}$ of incubation, conditioned medium $(\mathrm{CM})$ was collected and stored at $-80^{\circ} \mathrm{C}$ for MMP/TIMP assays, and the phenotype of cultured cells was determined by immunolabeling for specific markers.

Cell immunolabeling. Cytokeratin/vimentin immunolabeling allowed reciprocal contamination of AECs and fibroblasts to be determined. T1 $\alpha$ and surfactant protein B (SP-B) characterized ATI and ATII, respectively. Methanol-fixed cells were incubated for $1 \mathrm{~h}$ either with monoclonal anti-rat pan-cytokeratin antibody (Sigma Chemical Co.), monoclonal anti-rat vimentin antibody (Santa Cruz Biotechnology, Santa Cruz, CA), rabbit anti-rat SP-B antibody (gift from Prof. J.A. Whitsett, Cincinnati OH), or monoclonal anti-rat T1 $\alpha$ antibody (gift from Prof. M.C. Williams, Boston, MA). fluorescein isothiocyanate-conjugated anti-mouse immunoglobulin antibody (Jackson Immunoresearch Labs, Soham, Cambridgeshire, UK), or Texas redconjugated anti-rabbit immunoglobulin antibody (GE Healthcare, Orsay, France) were used as secondary antibodies. Cell nuclei were labeled with bisbenzimide (Sigma Chemical Co.). Fluorescence was viewed on a Zeiss Axioskop-40 microscope.

RNA extraction. Total RNA was isolated using Trizol reagent (Invitrogen, Cergy-Pontoise, France), pelleted, dissolved in sterile water, and quantified by absorbance at $260 \mathrm{~nm}$ (Biophotometer, Eppendorf). Integrity was checked by denaturing gel electrophoresis.

cDNA probes and Northern blot analysis. Total rat lung RNA was reverse transcribed using Superscript II reverse transcriptase and random hexamer primers (Invitrogen). Probes were amplified by polymerase chain reaction using target-specific primer sequences (Table 1), labeled with $\left(\alpha^{32} \mathrm{P}\right)$ deoxycytidine triphosphate (NEN, Perkin Elmer) using Rediprime labeling system (GE Healthcare), and purified on G-50 columns (GE Healthcare). For Northern blot analysis, $20 \mu \mathrm{g}$ of RNA was electrophoresed on $1.2 \%$ agarose, $2.2-\mathrm{M}$ formaldehyde gels and then transferred to nylon membranes (Gene Screen, Perkin Elmer). Membranes were successively probed for TIMP-1, TIMP-2, MT1-MMP, MMP-2 mRNA, and 18S rRNA in buffer containing 50\% formamide, $50 \mathrm{mM}$ Tris- $\mathrm{HCl}(\mathrm{pH} 7.5), 0.8 \mathrm{M} \mathrm{NaCl}, 10 \%$ dextran sulfate, $0.1 \%$ sodium pyrophosphate, $5 \times$ Denhardt solution, $0.1 \%$ sodium dodecylsulfate (SDS), and $75 \mu \mathrm{g} / \mathrm{mL}$ denatured salmon sperm DNA. Hybridization was run overnight at $42^{\circ} \mathrm{C}$. Blots were exposed to X-Omat AR Kodak films at $-80^{\circ} \mathrm{C}$. Autoradiographic signals were quantified by densitometry $(\mathrm{NIH}$ Image, Bethesda, MD) and normalized to $18 \mathrm{~S}$ rRNA.

Zymography for determination of MMP-2 and MMP-9 gelatinase activities. Equal volumes of $\mathrm{CM}$ collected from equal number of cells were electrophoresed under nonreducing conditions on $8 \%$ SDS-polyacrylamide gels impregnated with $0.5 \mathrm{mg} / \mathrm{mL}$ of gelatin before casting. Gels were washed for $30 \mathrm{~min}$ in $2.5 \%$ Triton X-100 to remove the SDS, then incubated overnight at $37^{\circ} \mathrm{C}$ in digestion buffer $(50 \mathrm{mM}$ Tris- $\mathrm{HCl}$ and $10 \mathrm{mM} \mathrm{CaCl} 2, \mathrm{pH}$ 7.4). Gels were stained with Coomassie blue (R250) to reveal unstained areas where the substrate was degraded by proteases. Attribution of activities to MMPs was confirmed by inhibition in the presence of ethylenediamine tetraacetic acid $(10 \mathrm{mM})$. Densitometry was achieved with NIH Image software.

Reverse zymography for determination of TIMP activities. Equal volumes of CM collected from equal number of cells were electrophoresed on $13 \%$ SDS-polyacrylamide gels containing both gelatin $(0.5 \mathrm{mg} / \mathrm{mL})$ and gelatinase-rich solution produced by fetal rat lung fibroblasts stimulated by phorbol ester 12-tetradecanoylphorbol-13 acetate (20). Gels were washed and incubated for $10 \mathrm{~h}$ in digestion buffer at $37^{\circ} \mathrm{C}$ and then stained as for zymography. TIMP activities revealed as dark bands on a light background because of gelatinase-inhibiting activity. Bands were identified by their molecular weight and comparison to a recombinant human TIMP-2 standard (gift from Prof. G. Murphy, Cambridge, UK). Densitometry was achieved with NIH Image software.

Statistical analysis. Data are presented as mean \pm SE. Multiple comparisons of mean values were made by analysis of variance (ANOVA) and Fisher's protected least significant difference (PLSD), or by nonparametric Kruskal-Wallis analysis and Mann-Whitney $U$ test, depending on applicability. $p=0.05$ was considered as the limit of statistical significance.

\section{RESULTS}

Characterization of isolated cells. AECs and fibroblasts displayed characteristic morphologic features of their cell type (Fig. $1 A$ and $C$ ) and strongly expressed cytokeratin (Fig. $1 B$ ) and vimentin (Fig. $1 D$ ), respectively. Reciprocal contaminations were $<5 \%$ of vimentin-positive cells in AECs and $<2 \%$ of cytokeratin-positive cells in fibroblasts.

Developmental expression of MT1-MMP. In fibroblasts, MT1-MMP-mRNA level changed little before birth (Fig. 2A and $B$ ). It increased four- to fivefold on pn3, remained ele-

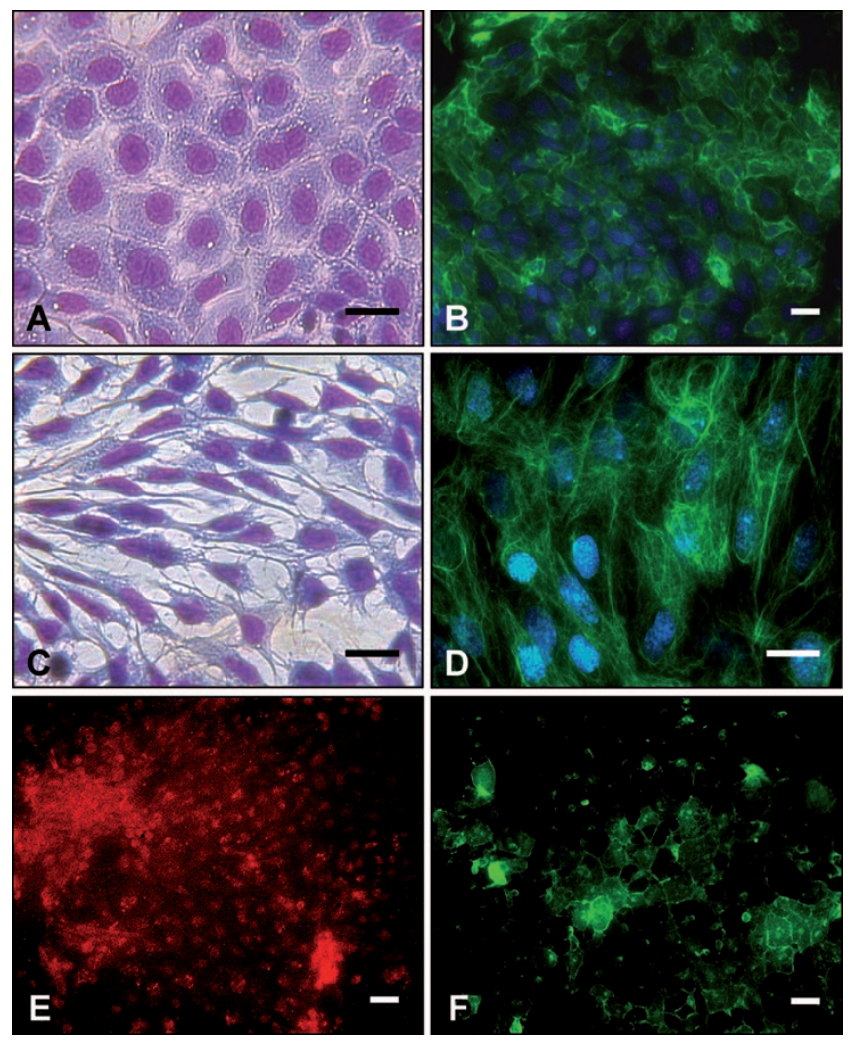

Figure 1. Characterization of isolated and cultured lung cells. Hematoxylineosin staining showed polygon-shaped AECs in monolayers $(A)$, whereas fibroblasts were spindle shaped $(C)$. AECs strongly labeled for cytokeratin $(B)$ and fibroblasts for vimentin $(D)$; nuclear counterstaining with bisbenzimide. Cells cultured on CFL matrix immunostained positively for both the ATII marker SP-B $(E)$ and the ATI marker T1 $\alpha(F)$. Bars $=20 \mu \mathrm{m}$. 


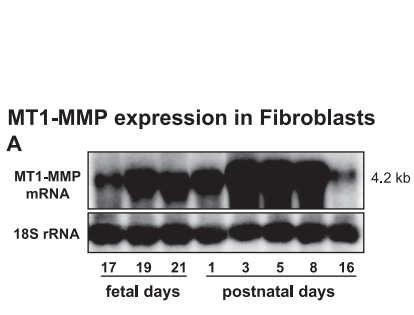

B

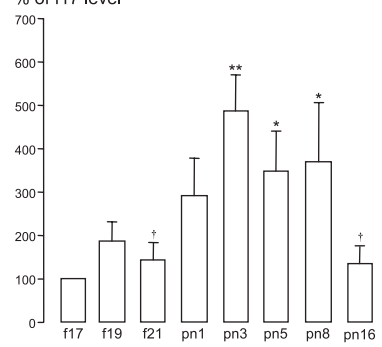

MT1-MMP expression in AEC

D

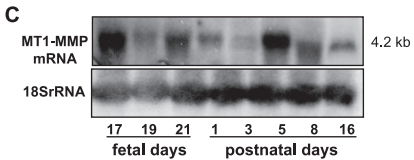

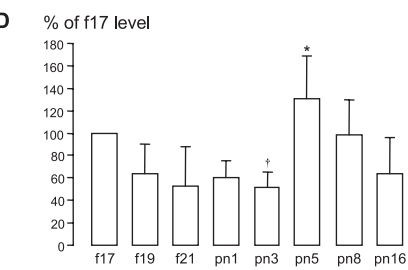

Figure 2. MT1-MMP mRNA expression in fetal and postnatal lung fibroblasts $(A, B)$ and AECs $(C, D)$. $(A$ and $C)$ Representative Northern blots. $(B$ and $D$ ) Densitometric analysis of relative mRNA abundance normalized for loading by $18 \mathrm{~S}$ rRNA. Mean $\pm \mathrm{SE}$ of five independent determinations run in five different cell preparations from different litters. Multiple comparisons by ANOVA and Fisher's PLSD. Significant difference for fibroblasts $(B)$ : ${ }^{*} p<$ 0.05 vs f17; **p $<0.01$ vs f17; $\dagger p<0.05$ vs pn3 or pn8 and for AECs $(D)$ : $* p<0.05$ vs pn $3 ; \dagger p<0.05$ vs f17.

vated until pn8, and then returned to prenatal level on pn16. In AECs, the expression level did not change significantly from f17 to pn1, but in contrast with fibroblasts, it was slightly, but significantly, decreased on pn3. A transient increase to 2.5 times the pn3 level and 1.3 times the 17 level occurred on pn5 (Fig. 2C and D). During alveolarization, comparison on same blot indicated that lung fibroblasts expressed approximately twice more MT1-MMP mRNA than epithelial cells (not shown).

Developmental expression of MMP-2. MMP-2 expression did not change significantly in fibroblasts during the period under study (Fig. 3A and $B$ ). In AECs, by contrast, it increased $50 \%$ from $\mathrm{f} 17$ to $\mathrm{f} 19$, when it was maximal coincidentally with the start of ATII differentiation; it decreased then on f21 and further decreased after birth. A slight and transient increase occurred on pn5 (Fig. 3C and D).

Developmental expression of TIMP-1 and TIMP-2. In fibroblasts (Fig. $4 A$ and $B$ ), TIMP-1 and TIMP-2 mRNAs were rather weakly expressed on $\mathrm{f} 17$ as compared with later stages; they increased two- and threefold, respectively, between $\mathrm{f} 17$ and $\mathrm{f} 19$, then remained stable until pn1. For both TIMPs, a sharp and tremendous increase occurred on pn3 (four to five times the pn1 level). Expression levels decreased thereafter progressively to retrieve prenatal levels on pn8. Expression patterns of both TIMPs were strikingly similar. In AECs (Fig. 2C and D), TIMP-1 mRNA level decreased approximately $75 \%$ with advancing gestation, whereas that of TIMP-2 mRNA remained constant. Both TIMP mRNAs increased between pn3 and pn5 to reach twice the f17 level, then remained constant through pn16. Comparison of fibroblasts and AECs on same blots indicated similar levels, except on pn3, when there were higher levels in fibroblasts (not shown).
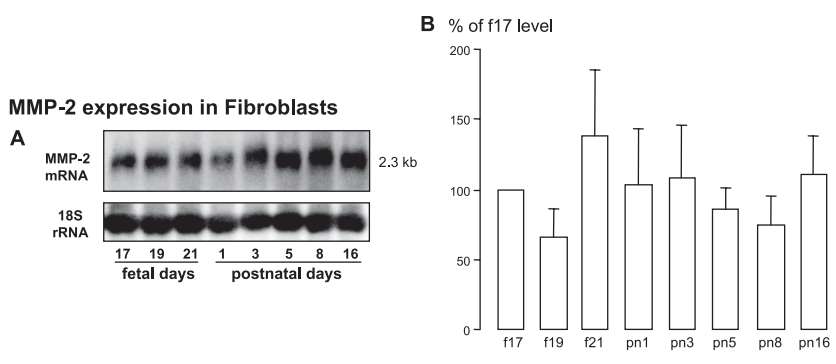

MMP-2 expression in AEC
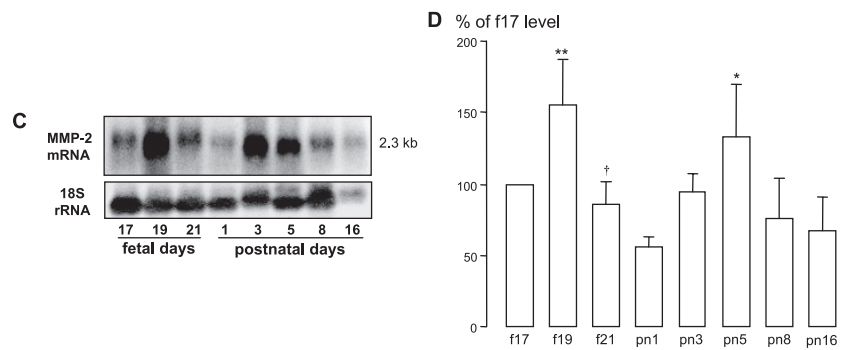

Figure 3. MMP-2 mRNA expression in fetal and postnatal lung fibroblasts $(A, B)$ and AECs $(C, D)$. ( $A$ and $C)$ Representative Northern blots. $(B$ and $D)$ densitometric analysis of relative mRNA abundance normalized for loading by $18 \mathrm{~S}$ rRNA. Mean $\pm \mathrm{SE}$ of five independent determinations run in five different cell preparations from different litters. Multiple comparisons by ANOVA and Fisher's PLSD. Significant differences for AECs $(D)$ : * $p<0.05$ vs pn $1 ; * * p<0.001$ vs pn $1 ; \uparrow p<0.05$ vs f19. Changes in fibroblasts did not reach significance level.
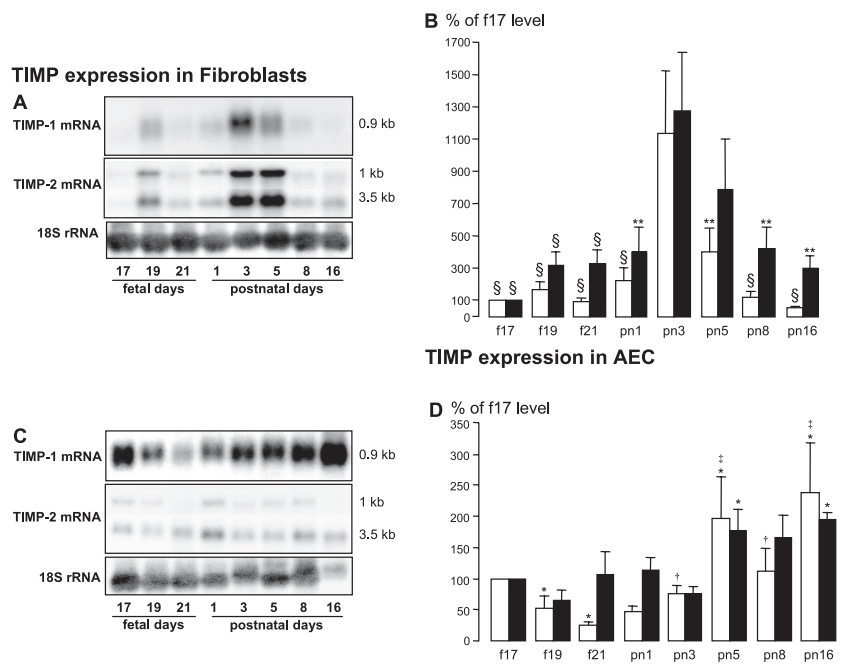

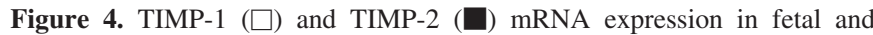
postnatal lung fibroblasts $(A, B)$ and $\operatorname{AECs}(C, D)$. ( $A$ and $C$ ) Representative Northern blots of TIMP-1 and TIMP-2 mRNAs in fibroblasts and AECs, respectively. ( $B$ and $D$ ) Densitometric analysis of relative mRNA abundance normalized for loading by $18 \mathrm{~S}$ rRNA. Mean $\pm \mathrm{SE}$ of five independent determinations run in five different cell preparations from different litters. Multiple comparisons by ANOVA and Fisher's PLSD. Significant difference for fibroblasts $(B): * p<0.05$; **p $<0.01 ; \S p<0.001$ vs pn3, and for AECs $(D): * p<0.05 v s$ f17; $\uparrow p<0.05 v s$ f 21 and pn $1, \ddagger p<0.01$ vs $\mathrm{f} 21$ and pn1.

Differential production of MMPs/TIMPs by cells expressing ATI or ATII phenotype. AECs cultured on EHS matrix massively expressed SP-B and failed to express T1 $\alpha$, whereas AECs cultured on plastic or CF stained positively for $\mathrm{T} 1 \alpha$, but not for SP-B (not shown). They were therefore considered as ATII and ATI, respectively. Cells cultured on CFL simultaneously expressed SP-B and T1 $\alpha$ (Fig. $1 E$ and $F$ ), therefore 

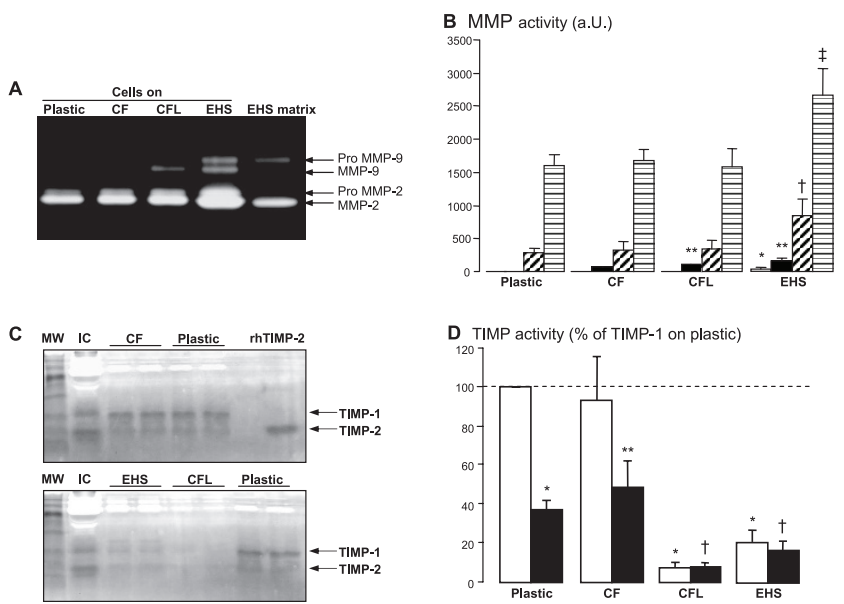

Figure 5. Comparison of gelatinase (MMP-2 and -9) and TIMP-1 and -2 activities released in CM by AECs cultured on different substrata. ( $A$ and $B$ ) Gelatinase activities evaluated by zymography. (A) Representative zymogram of CM from cells on plastic, CF, CFL, or EHS matrix, and from EHS matrix without cells. Gelatinolytic activities appear as strong bands for MMP-2 (目)

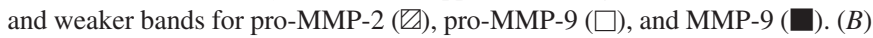
densitometric analysis (arbitrary units, a.U.); activity from EHS matrix alone was subtracted from total activity to determine the part due to AECs cultured on this substratum. ( $C$ and $D$ ) TIMP activities evaluated by reverse zymography. (C) Representative reverse zymograms of $\mathrm{CM}$ from cells on $\mathrm{CF}$, plastic, EHS, and CFL. MW, molecular weight markers; IC, internal control (Dulbecco modified Eagle medium-10\% FBS); rhTIMP-2, recombinant human TIMP-2 used as positive control. Gelatinolytic-inhibiting activities appeared as zones of positive staining with Coomassie blue, with two major areas at 28 (TIMP-1: $\square$ ) and $21 \mathrm{kD}$ (TIMP-2: $\square$ ). (D) Densitometric analysis. Data are mean \pm SE of three independent determinations (different cell culture experiments). Multiple comparisons by Kruskal-Wallis analysis and Mann-Whitney $U$ test. Significant difference in $B$ : ${ }^{*} p<0.001 v s$ pro-MMP-9 on plastic; $* * p<0.001$ vs MMP-9 on plastic; $\dagger p<0.001$ vs pro-MMP-2 on plastic; and $\ddagger p<0.01$ vs MMP-2 on plastic. Significant difference in $D: * p<0.001$ vs TIMP-1 on plastic; $* * p<0.01$ vs TIMP- 1 on CF; $\dagger p<$ 0.01 vs TIMP-2 on CF.

displaying an ATI-ATII intermediary phenotype. As shown in Figure $5 A$ and $B$, cells produced similar MMP-2 amounts on all substrata, except on EHS matrix where the activity was $45 \%$ higher. Only cells grown on EHS matrix or CFL released MMP-9, although in much lower proportion than MMP-2. Cells on CFL displayed secretion features intermediary between those of cells on CF and EHS matrix. As depicted in Figure $5 C$ and $D$, TIMP-1 activity from cells on plastic or CF was approximately nine- and fivefold higher than that from cells on CFL and EHS matrix, respectively, and threefold greater activity was observed for TIMP-2. On plastic and CF, TIMP-1 activity was about twice TIMP- 2 activity, whereas on EHS matrix or CFL, both TIMPs presented similar levels (Fig. $5 D$ ). The MMP/TIMP balance therefore appears in favor of greater proteolytic activity for cells on CFL or EHS matrix.

\section{DISCUSSION}

The MMP/TIMP system plays a key role in epithelialmesenchymal interactions that are essential for lung development. We profiled the expression of key members of the MMP and TIMP families in lung fibroblasts and AECs isolated at various stages, and tentatively correlated variations with morphologic changes. We demonstrated quite different patterns among cell types, which shows that previously reported changes in whole lung were not informative enough to understand all developmental implications.

Using isolated cells is a possible limitation of this study because we cannot rule out the possibility that cell isolation might have altered transcript levels to some extent. The study, however, allowed developmental changes to be evidenced that are unlikely to be due to cell processing. Similarly, the low reciprocal contaminations of fibroblasts and AECs are unlikely to have altered the results because changes in one cell type were not reflected in the other. For instance, the marked increase in MT1-MMP or TIMP mRNA levels in fibroblasts on pn3 went along with no change or a decrease in AECs. Such possible bias would indeed be avoided by in situ hybridization or immunohistochemistry, but these approaches can hardly provide precise quantitative determination and are no more exempt of limitations. Thus, they sometimes led to contradictory results, with either no expression of MMP-9 in fetal rat lung (12) and of TIMP-1 in fetal rabbit lung (7) or, conversely, expression of MMP-9 in fetal rat (21) or monkey (11) lung and of TIMP-1 in monkey (11) or human and mouse (8) lung. Another limitation resides in the impossibility to determine MMP/TIMP activities in freshly isolated cells because collecting medium with released material implies several hours of culture, which may have induced still greater changes than cell isolation. Except in the instance of ATI/ATII comparison, we had therefore to limit our investigation to the pretranslational level and to infer from expression changes for putative changes in activity. Last, although we previously showed that AECs isolated by this procedure expressed specific ATII markers (17), we cannot exclude that part of cells herein designated AECs were in fact Clara cells that also express SP-B. This, however, was unlikely to interfere with our primary finding of differences between epithelial cells and fibroblasts.

A major finding consisted in localizing considerable changes in MT1-MMP expression to fibroblasts during alveolarization, which was not evident from previous global profiling studies (5) or examinations of expression including in situ hybridization in mice $(13,14)$. In addition, the lack of a relationship among MMP-2, TIMPs, and MT1-MMP was unexpected based on previous whole-lung profiling data (5). Alveolarization comprises a period of alveolar-sac proliferation that occurs before birth, a period of secondary septation that takes places from 4 to $14 \mathrm{pn}$ in the rat, and finally a period of wall thinning and microvascular maturation with fusion of the double capillary network into a single network (2). Peak expression of MT1-MMP in fibroblasts between pn3 and pn8, followed by decrease on pn16, suggests a link with septation process. Moreover, although much less striking, maximal level was also achieved in AECs during the same period, on pn5. Previous findings from in situ hybridization in mice indicating peak expression in alveolar walls around d 10 are also consistent with this hypothesis (14). High MT1-MMP expression in this period is in keeping with its essential role in alveolar development recently demonstrated by the lack of septation in MT1-MMP-deficient mice $(13,14)$. Although other cell types including endothelial cells could also contrib- 
ute, our findings argue in favor of a major contribution of fibroblasts in producing MT1-MMP during alveolarization. With regard to its mechanism of action, although MT1-MMP is known to activate pro-MMP-2 (22), its role in alveolarization appears to be largely independent from this ability $(13,14)$. Consistently, MMP-2-null mice have only limited alveolarization defects $(12,13)$, and we did not find significant changes in MMP-2 expression in fibroblasts during lung development. Taking into account the cell motility-promoting and invasion-promoting activities of MT1-MMP (23), on the one hand, and the requirement of myofibroblast migration for elastin deposition and alveolarization (24) on the other, an essential role of MT1-MMP in myofibroblast migration to locations where secondary septa surge is a likely hypothesis. Because MT1-MMP favors neovessel formation (25), it may also be crucial for microvascular development (13), an essential component of alveolarization.

In contrast with fibroblasts, MMP-2 expression in AECs fluctuated with development, which is likely to have functional significance. A first peak of expression on $\mathrm{f} 19$ presumably correlated with formation of basement membrane (BM) discontinuities underneath ATII through which foot processes protrude and establish contact with lipofibroblasts $(26,27)$. ATII maturation correlates with increased frequency of those BM discontinuities that appear essential to epithelialmesenchymal interactions $(26,27)$. Interestingly, our investigation also demonstrated that ATII present higher matrix proteolytic potential than ATI, which is likely to be in connection with the preferential association of membrane discontinuities with the former. In agreement with our findings, AECs cultured on plastic presented higher collagenolytic activity after $2 \mathrm{~d}$ of culture than after $7 \mathrm{~d}$ (28), which probably reflects conversion from ATII to ATI phenotype on this substratum. Moreover, the decreased MMP-2 expression observed in AECs between f19 and f21 (Fig. 4) may reflect the increased proportion of ATI between both stages (2). After a decrease around birth, a second peak of MMP-2 expression was observed on pn5. Its significance is unclear. It does not seem to relate to $\mathrm{BM}$ discontinuities that regularly decrease after birth (27), and, contrary to the peak of MT1-MMP expression in fibroblasts, it was not maintained throughout alveolar septation. Nevertheless, it was reported that infants evolving toward bronchopulmonary dysplasia present decreased MMP-2 and increased MMP-9 activities in tracheal effluent $(10,11)$. These changes are likely to represent altered release by epithelial cells. Because alveolarization is impaired in the disease, they suggest functional importance of elevated epithelial MMP-2 expression when alveolarization starts, although its precise role is unknown.

TIMP-1 expression was found to be minimal in both fibroblasts and AECs at the end of gestation and to diminish with maturation in AECs. During the corresponding canalicular and saccular stages, air-blood barriers appear and develop, matrix material reduces, and foot processes increase in number. Assuming reflected changes in activity, a low TIMP-1 level may favor proteolytic activity necessary to degrade ECM during these processes. Although striking, the expression peak of TIMP-1 and -2 in fibroblasts on pn3 may, by contrast, not be related to a particular developmental event because it occurs at a time when the lung presents little change after prenatal surfactant accumulation and before the start of alveolarization. Minoo et al. (29) previously reported similar TIMP-1 mRNA increase in neonatal baboon whole lung after premature or term birth. Its presence in premature neonates led to consider this increase as a consequence of passage to oxygen breathing (29). Our findings are likely to represent the same phenomenon. The significance of this transient increase is unclear, but whether it was reflected in higher TIMP activity, it seems likely to be associated with limited postnatal ECM remodeling. Postnatally, both TIMP-1 and -2 transcripts increased progressively in AECs and stayed maximal between pn5 and pn16. In fibroblasts, by contrast, TIMP-1 and -2 expression declined from pn5 to pn8 and reached a particularly low level on pn16. High levels in AECs may correspond to progression and stabilization of BM with decreased frequency of discontinuities (27). Relatively high expression level of TIMPs in both compartments during septation may also facilitate secondary crest formation by limiting degradation of soluble elastin (tropoelastin) before stabilization by cross-linkage. Last, since TIMPs promote cell growth independently of their MMP-inhibiting effects (30,31), high TIMP levels in postnatal weeks may contribute to the intense cell proliferation observed for all cell types at this time (2). Reciprocally, decreased TIMP expression in fibroblasts after completion of septation may correlate with thinning of the interstitial compartment that occurs in this last developmental stage (2).

As a whole, this study brings new insights into MMP/TIMP expression in the developing lung, pointing out the importance of distinguishing between different cells. In the perspective of preventing diseases that include changes in MMP activities, particularly bronchopulmonary dysplasia, changes in various cell compartments should be documented.

Acknowledgments. The authors thank Dr. Patricia Rousselle (Institut de Biologie et Chimie des Protéines, Lyon, France) for the gift of purified laminin 5.

\section{REFERENCES}

1. McGowan SE 1992 Extracellular matrix and the regulation of lung development and repair. FASEB J 6:2895-2904

2. Burri PH 1984 Fetal and postnatal development of the lung. Annu Rev Physiol 46:617-628

3. Visse R, Nagase H 2003 Matrix metalloproteinases and tissue inhibitors of metalloproteinases: structure, function, and biochemistry. Circ Res 92:827-839

4. Rolland G, Xu J, Tanswell AK, Post M 1998 Ontogeny of extracellular matrix gene expression by rat lung cells at late fetal gestation. Biol Neonate 73:112-120

5. Nuttall RK, Zampieri CL, Pennington CJ, Gill SE, Schultz GA, Edwards DR 2004 Expression analysis of the entire MMP and TIMP gene families during mouse tissue development. FEBS Lett 563:129-134

6. Rolland G, Xu J, Dupret JM, Post M 1995 Expression and characterization of type IV collagenases in rat lung cells during development. Exp Cell Res 218:346-350

7. Fukuda Y, Ishizaki M, Okada Y, Seiki M, Yamanaka N 2000 Matrix metalloproteinases and tissue inhibitor of metalloproteinase-2 in fetal rabbit lung. Am J Physiol Lung Cell Mol Physiol 279:L555-L561

8. Ryu J, Vicencio AG, Yeager ME, Kashgarian M, Haddad GG, Eickelberg O 2005 Differential expression of matrix metalloproteinases and their inhibitors in human and mouse lung development. Thromb Haemost 94:175-183

9. Shannon JM, Hyatt BA 2004 Epithelial-mesenchymal interactions in the developing lung. Annu Rev Physiol 66:625-645

10. Danan C, Jarreau PH, Franco ML, Dassieu G, Grillon C, Abd Alsamad I, Lafuma C, Harf A, Delacourt C 2002 Gelatinase activities in the airways of premature infants and development of bronchopulmonary dysplasia. Am J Physiol Lung Cell Mol Physiol 283:L1086-L1093 
11. Tambunting F, Beharry KD, Hartleroad J, Waltzman J, Stavitsky Y, Modanlou HD 2005 Increased lung matrix metalloproteinase-9 levels in extremely premature baboons with bronchopulmonary dysplasia. Pediatr Pulmonol 39:5-14

12. Kheradmand F, Rishi K, Werb Z 2002 Signaling through the EGF receptor controls lung morphogenesis in part by regulating MT1-MMP-mediated activation of gelatinase A/MMP2. J Cell Sci 115:839-848

13. Oblander SA, Zhou Z, Galvez BG, Starcher B, Shannon JM, Durbeej M, Arroyo AG, Tryggvason K, Apte SS 2005 Distinctive functions of membrane type 1 matrixmetalloprotease (MT1-MMP or MMP-14) in lung and submandibular gland development are independent of its role in pro-MMP-2 activation. Dev Biol 277:255-269

14. Atkinson JJ, Holmbeck K, Yamada S, Birkedal-Hansen H, Parks WC, Senior RM 2005 Membrane-type 1 matrix metalloproteinase is required for normal alveolar development. Dev Dyn 232:1079-1090

15. Wang Z, Juttermann R, Soloway PD 2000 TIMP-2 is required for efficient activation of proMMP-2 in vivo. J Biol Chem 275:26411-26415

16. Gill SE, Pape MC, Khokha R, Watson AJ, Leco KJ 2003 A null mutation of tissue inhibitor of metalloproteinases-3 (TIMP-3) impairs murine bronchiole branching morphogenesis. Dev Biol 261:313-323

17. Chelly N, Mouhieddine-Gueddiche OB, Barlier-Mur AM, Chailley-Heu B, Bourbon JR 1999 Keratinocyte growth factor enhances maturation of fetal rat lung type II cells. Am J Respir Cell Mol Biol 20:423-432

18. Shannon JM, Emrie PA, Fisher JH, Kuroki Y, Jennings SD, Mason RJ 1990 Effect of a reconstituted basement membrane on expression of surfactant apoproteins in cultured adult rat alveolar type II cells. Am J Respir Cell Mol Biol 2:183-192

19. Isakson BE, Lubman RL, Seedorf GJ, Boitano S 2001 Modulation of pulmonary alveolar type II cell phenotype and communication by extracellular matrix and KGF. Am J Physiol Cell Physiol 281:C1291-C1299

20. Xu J, Liu M, Post M 1999 Differential regulation of extracellular matrix molecules by mechanical strain of fetal lung cells. Am J Physiol 276:L728-L735

21. Tatekawa Y, Kanehiro H, Hisanaga M, Nakajima Y 2003 Matrix metalloproteinase-9 and tissue inhibitor of metalloproteinase-1: expression in the lung of fetal rats with nitrofen-induced diaphragmatic hernia. Pediatr Surg Int 19:25-28
22. D'Ortho MP, Will H, Atkinson S, Butler G, Messent A, Gavrilovic J, Smith B, Timple R, Zardi L, Murphy G 1997 Membrane-type matrix metalloproteinases 1 and 2 exhibit broad-spectrum proteolytic capacities compatible to many matrix metalloproteinases. Eur J Biochem 250:751-767

23. Itoh Y, Seiki M 2006 MT1-MMP: a potent modifier of pericellular microenvironment. J Cell Physiol 206:1-8

24. Lindahl P, Karlsson L, Hellstrom M, Gebre-Medhin S, Willetts K, Heath JK, Betsholtz C 1997 Alveogenesis failure in PDGF-A-deficient mice is coupled to lack of distal spreading of alveolar smooth muscle cell progenitors during lung development. Development 124:3943-3953

25. Chun TH, Sabeh F, Ota I, Murphy H, McDonagh KT, Holmbeck K, BirkedalHansen H, Allen ED, Weiss SJ 2004 MT1-MMP-dependent neovessel formation within the confines of the three-dimensional extracellular matrix. J Cell Biol 167:757-767

26. Leung CK, Adamson IY, Bowden DH 1980 Uptake of $3 \mathrm{H}$ prednisolone by fetal lung explants: role of intercellular contacts in epithelial maturation. Exp Lung Res 1:111-120

27. Grant MM, Cutts NR, Brody JS 1983 Alterations in lung basement membrane during fetal growth and type II cell development. Dev Biol 97:173-183

28. Pardo A, Ridge K, Uhal B, Sznajder JI, Selman M 1997 Lung alveolar epithelial cells synthesize interstitial collagenase and gelatinases $\mathrm{A}$ and $\mathrm{B}$ in vitro. Int J Biochem Cell Biol 29:901-910

29. Minoo P, Penn R, deLemos DM, Coalson JJ, deLemos RA 1993 Tissue inhibitor of metalloproteinase-1 mRNA is specifically induced in lung tissue after birth. Pediatr Res 34:729-734

30. Hayakawa T, Yamashita K, Tanzawa K, Uchijima E, Iwata K 1992 Growthpromoting activity of tissue inhibitor of metalloproteinases-1 (TIMP-1) for a wide range of cells. A possible new growth factor in serum. FEBS Lett 298:29-32

31. Hayakawa T, Yamashita K, Ohuchi E, Shinagawa A 1994 Cell growth-promoting activity of tissue inhibitor of metalloproteinases-2 (TIMP-2). J Cell Sci 107:23732379 